\title{
From automatization to neurophenomenology of artificial intelligence in robotics
}

\begin{abstract}
The main problem in robotics is strengthening of robot artificial intelligence ( $\left.\mathrm{I}_{2}\right)$ system. Its solution will facilitate cooperation of man with robot. Authors suggest advanced technology for $\mathrm{I}_{\mathrm{A}}$ development. It borrows method of universal (deep) tutoring $\left(\mathrm{T}_{\mathrm{U}}\right)$ relying on semantic axiomatic method (AM). By method $\mathrm{T}_{\mathrm{U}}$ knowledge understanding is achieved by rational consciousness formation. It uses the utmost mathematical abstractions expressed on language of categories $\left(\mathrm{L}_{\mathrm{C}}\right)$. Being functional one $\mathrm{L}_{\mathrm{C}}$ is destined for intellectual processes $\left(\mathrm{P}_{\mathrm{IR}}\right)$ description due to its universal constructions. Following $\mathrm{T}_{\mathrm{U}}$ robot educational space $\left(\mathrm{S}_{\mathrm{ER}}\right)$ is class of categories. Its $\mathrm{I}_{\mathrm{A}}$ sophistication occurs through new categories inclusion as required in robot $\mathrm{I}_{\mathrm{A}}$ multilevel hierarchical orientated network $\left(\mathrm{N}_{\mathrm{C}}\right)$ of concepts. Universal laws of robot functioning are embodied as operations of algebraic structures being objects of $\mathrm{N}_{\mathrm{C}}$. It creates integrated environment of applications $\left(\mathrm{IE}_{\mathrm{A}}\right)$. Robot intercourse with man and its interaction with working space $\left(\mathrm{S}_{\mathrm{WR}}\right)$ make active $\mathrm{P}_{\mathrm{IR}}$ happening in $\mathrm{N}_{\mathrm{C}}$. Processes of assignments execution $\left(\mathrm{P}_{\mathrm{ER}}\right)$ begin just when satisfaction to a set of relations in $\mathrm{S}_{\mathrm{WR}}$ and in robot space of notions is a success. Possibility of $\mathrm{P}_{\mathrm{IR}}$ to climb up the highest levels of $\mathrm{N}_{C}$ and down the lowest ones endows robot with capability to generate $\mathrm{P}_{\mathrm{ER}}$ making decisions in unfamiliar $\mathrm{S}_{\mathrm{WR}}$.
\end{abstract}

Keywords: neurophenomenology, universal tutoring, artificial intelligence, language of categories, functor, free algebra, algebraic system, abstract type of data, intellectual process, execution process, context
Volume 4 Issue I - 2018

\section{Gromyko V,' Vasilyev NS²}

'Department of Computing Mathematics and Cybernetics, Lomonosov Moscow State University, Russia

${ }^{2}$ Department of Fundamental Sciences, Bauman Moscow State Technical University, Russia

Correspondence: Vasilyev NS, Department of Fundamental Sciences, Bauman Moscow State Technical University, Russia, Email nik8519@yandex.ru

Received: November 05, 2017 | Published: January 03, 2018
Abbreviations: $\mathrm{I}_{\mathrm{A}}$, artificial intelligence; $\mathrm{T}_{\mathrm{U}}$, universal tutoring; $\mathrm{AM}$, axiomatic method; $\mathrm{A}_{\mathrm{F}}$, free algebras; $\mathrm{S}_{\mathrm{A}}$, algebraic system; $\mathrm{S}_{\mathrm{ER}}$, robot educational space; $\mathrm{P}_{\mathrm{IR}}$, robot intellectual processes; In Lib, inter subject library; $\mathrm{P}_{\mathrm{EdSpSs}}$, personal educational semantic space.

\section{Introduction}

Authors' purpose is to clarify how one can train robot $\mathrm{I}_{\mathrm{A}}$ to higher levels of complexity. Intellectual technical units imitate anthropogenesis (Figure 1). So principles of human rational consciousness development can be applied to robot $\mathrm{I}_{\mathrm{A}}$ creation ${ }^{1}$ Table 1. Research carried out before discovered universal laws of human mind functioning. It was proved that in human rational consciousness creation the most important role plays universal ideas of mathematics expressed on language of categories, ${ }^{2}$ Figure $1 \mathrm{~b}$. Meanings of the whole theories can be described on $\mathrm{L}_{\mathrm{C}}$ in the form of categories. Method of $T_{U}$ is proposed as basis of advanced technology of intellect perfection. It realizes projective method of teaching. The approach allows constructing multilevel net of robot notions $\mathrm{N}_{\mathrm{C}}$ as base of $I_{A}$, see Figure 1b. It differs from inductive approach used in robotics to designing of clever specialized machines. ${ }^{3}$. Usually separate robot functions in it are gradually extended up to the partial intellectual capabilities. By our opinion with the help of general $P_{I R}$ complex behavior in the form of $\mathrm{P}_{\mathrm{ER}}$ can be obtained from simple robot actions. It becomes significant to create media for universal $P_{I R}$ phenomenology.

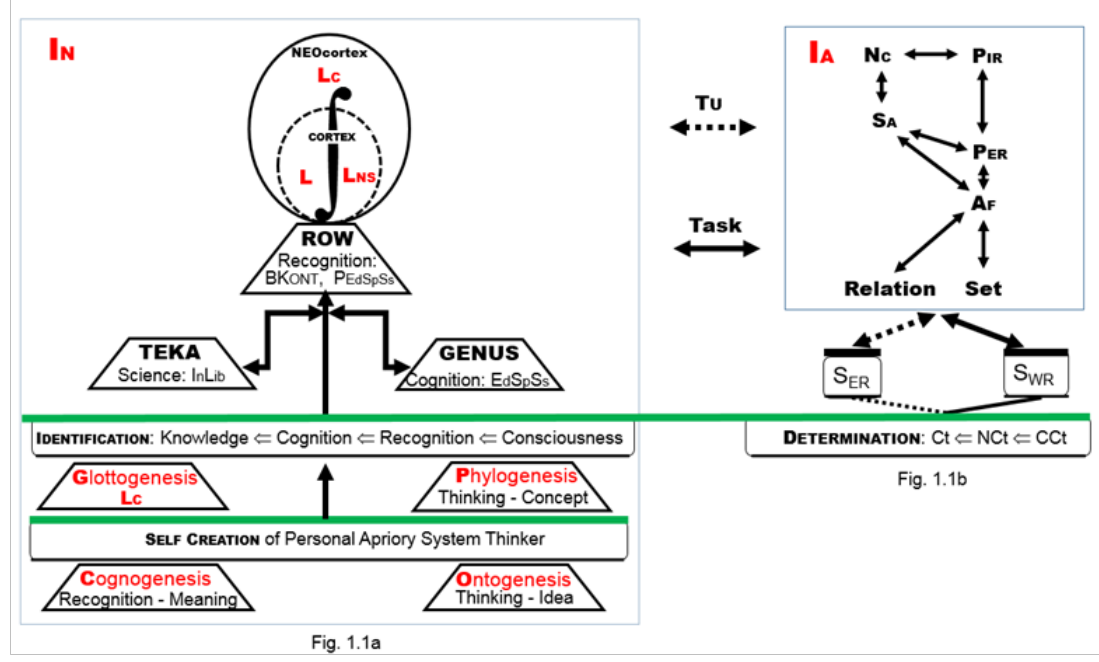

Figure I Functional Model - a) Natural Intellect $I_{N^{\prime}}$ b) Multilevel Robot $I_{A}$ System. 


\section{Table I Abbreviations}

\begin{tabular}{|c|c|}
\hline $\begin{array}{l}I_{A}\left(I_{N}\right) \text {, Artificial Intelligence (Natural } \\
\text { Intellect) }\end{array}$ & $\mathrm{N}_{\mathrm{C}}$, Network of Categories \\
\hline $\mathrm{T}_{U}$, Universal Tutoring & $\mathrm{S}_{\mathrm{A}}$, Algebraic System \\
\hline $\begin{array}{l}S_{E R}\left(S_{W R}\right) \text {, Robot Educational } \\
\text { (Working) Space }\end{array}$ & $A_{p}$ Free Algebra \\
\hline $\begin{array}{l}P_{I R}\left(P_{E R}\right), \text { Robot Intellectual } \\
\text { (Executive) Processes }\end{array}$ & InLib, Inter Subject Library \\
\hline $\begin{array}{l}\mathrm{L},\left(\mathrm{L}_{\mathrm{NS}}, \mathrm{L}_{\mathrm{C}}\right) \text {, Language (of Natural } \\
\text { Science, of Categories) }\end{array}$ & $\begin{array}{l}\mathrm{BK}_{\mathrm{ONT}} \text { Ontological Knowledge } \\
\text { Base }\end{array}$ \\
\hline $\begin{array}{l}\mathrm{P}_{\text {Edspss }} \text {, Personal Educational Semantic } \\
\text { Space }\end{array}$ & $\begin{array}{l}\text { NCt \&CCt, Net \&Category of } \\
\text { Contexts }(\mathrm{Ct})\end{array}$ \\
\hline
\end{tabular}

\section{Universal tutoring of $\mathrm{I}_{\mathrm{A}}$}

Scientific means of system-informational culture are clarified due to mathematics. ${ }^{1,2}$ Generalization serves for comprehension. So technology of $T_{U}$ is grounded on semantic knowledge presentation. Cognitive and functional degrees of $\mathrm{I}_{\mathrm{A}}$ complexity can be given in the form of its multilevel system organization, see Figure $1 \mathrm{~b}$. The most general $\mathrm{I}_{\mathrm{A}}$ concepts are uplifted and disposed on the highest levels of $\mathrm{N}_{\mathrm{C}}$. Algebraic structures are objects of corresponding categories. Use of morphism allows comparing the objects in order to understand their semantics.

\section{Definition: Context is a set of relations among objects of some categories}

Robot is able to execute assignments described by quasi-functor $f_{i}^{\prime}: K_{i}^{\prime} \rightarrow L_{i}^{\prime}, i=1,2, \ldots, n$, which make transformations of contexts. Then robot is capable to fulfill task $f^{\prime}: K^{\prime} \rightarrow L^{\prime}$ where $K^{\prime}=K_{1}^{\prime} \cup \ldots \cup K_{n}^{\prime}$ and $L^{\prime}=L_{1}^{\prime} \cup \ldots \cup L_{n}^{\prime}$ are co-products in the category SET. ${ }^{4}$ If new problem is put to obtain context $L$ then robot tutoring consists in acquiring of knowledge about quasi-functor $\varphi: L \rightarrow L^{\prime}$. Cartesian square ${ }^{4}$

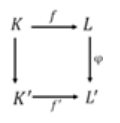

Defines inverse image $f: K \rightarrow L$ of morphism $f^{\prime}, \varphi$. Task $L$ execution corresponds to arrow $f$ application. It worth mentioning that context $K$ of $\mathrm{S}_{\mathrm{WR}}$ is unfamiliar to robot.

Example: Let $\mathrm{I}_{\mathrm{A}}$ be taught to recognize hand written letters using map $f^{\prime}$. The problem of robot training for texts recognition is to be solved. For the purpose robot must attain experience of quasi-funct $\varphi=(0, B T W)$ with operation 0 marking up start of text $L$. Relation BTW allows picking out text fragment lying between $0 L$ and any other letter $l$ of the text. Uplifting $f^{\prime}$ along $\varphi$ equips $\mathrm{I}_{\mathrm{A}}$ with the idea of linear order - arrow $f$.

\section{Universal functionality of $P_{E R}$}

Free algebras $\left(\mathrm{A}_{\mathrm{F}}\right)$ of $\mathrm{N}_{\mathrm{C}}$ become foundation of abstract types of data (ATD) interconnected by $\mathrm{N}_{C}$. Robot specialization is achieved by interpretation scheme of assignments fulfillment which takes in consideration working context. It is a matter of relations between $\mathrm{I}_{\mathrm{A}}$ notions in $\mathrm{N}_{\mathrm{C}}$ and states of $\mathrm{S}_{\mathrm{WR}}$. Knowledge description on $\mathrm{L}_{\mathrm{C}}$ corresponds to object oriented approach in programming. It also contributes to $I_{A}$ creation. Carriers of free algebras become definite by means of $\mathrm{S}_{\mathrm{WR}}$ and given task. It specializes ATD in $\mathrm{IE}_{\mathrm{A}}$ (Figure 1b). The utmost laws of $I_{A}$ functioning supplemented by $S_{W R}$ allow using context for $\mathrm{P}_{E R}$ starting. In this manner $\mathrm{I}_{\mathrm{A}}$ creative functions act. ${ }^{1}$ Besides that availability of $\mathrm{P}_{\mathrm{IR}}$ simplifies robot control system.

\section{Conclusion}

Proper to human mind neurophenomenology of $\mathrm{I}_{\mathrm{A}}$ is result of $\mathrm{P}_{\mathrm{IR}}$ interaction. Suggested advanced technology ensures growth of $\mathrm{N}_{C}$ levels in accordance with $\mathrm{I}_{\mathrm{A}}$ sophistication. It will amplify intellectual fields of robot adaptation.

\section{Acknowledgments \\ None.}

\section{Conflicts of interest}

No conflict of interest.

\section{References}

1. Gromyko VI, Kazaryan VP, Vasilyev NS, et al. Artificial Intelligence as Tutoring Partner for Human Intellect J AISC. 2018;658:238-247.

2. Gromyko VI, Kazaryan VP, Vasilyev NS, et al. Cconsciousness technology. J Complex Syst. 2016;1(3):46-61.

3. Yoshicazu Mori, Yuri Kumahara. Conceptual design of a portable robot inspiring elderly people to walk. Int $J$ Robotics \& Automation. 2017;3(3):1-2.

4. MacLane S. Categories for working mathematician. Phys Math Moscow. 2004. p. 1-364. 